\title{
Investigation and Study on the Implementation of Inquiry Teaching in Senior High School under New Teaching Reform
}

\author{
Shuang Yu and Guang $\mathrm{Li}^{*}$ * \\ College of Resource and Environment, Anshun University, Anshun 561000
}

\begin{abstract}
Keywords: New curriculum reform; Senior middle school; Inquiry teaching; Investigation and research
\end{abstract}

\begin{abstract}
This paper explores the implementation of inquiry teaching in high school teaching through a questionnaire survey. This paper analyzes the meaning of inquiry teaching; the paper also analyzes the characteristics of inquiry teaching and summarizes students' learning interest and motivation, experimental teaching situation, and classroom teaching methods.
\end{abstract}

\section{Introduction}

At present, the focus of teaching and research is shifting from knowledge transfer to capacity development, from the emphasis on results to the emphasis on processes. According to the teaching practice, a variety of teaching forms that adapt to differences and pay attention to the development of individuality, to make up for the insufficiency of the traditional teaching mode, have become an important trend in the reform of the teaching mode in the future[1]. The high school curriculum standard puts forward the concept of "enhancing scientific literacy and conducting exploratory learning in the classroom" by advocating inquiry teaching, cultivating students' independent scientific inquiry ability, and strengthening students' understanding of the nature of science. As a novel teaching method, the inquiry teaching method has a certain theoretical basis, effective teaching steps, and has a prominent feature superior to the general teaching methods[2].

\section{Explore the Concept of Teaching}

Studying the concept of inquiry teaching is helpful for my understanding of the nature of inquiry teaching. This will lay the theoretical foundation for the investigation and study of the implementation of inquiry teaching in practice[3].

\section{The Meaning of Scientific Inquiry}

Inquiry is a variety of different ways and methods used by people to pursue the exploration of unknowns in order to achieve "knowing what is happening and knowing the reasons of happening." It is also an important learning model for students to get knowledge and talent. The scientific inquiry that students perform in the classroom includes a series of activities. Simply speaking, inquiry is the process of finding problems and solving problems. It is a way of thinking of human beings, a method of finding evidence, and a process of understanding things. It is an important way and method to gain scientific understanding and master scientific skills[4].

\section{Inquiry Teaching}

Inquiry teaching is a type of teaching activity that takes inquiry as its basic feature. Specifically, it means that "the teaching process is under the guidance of the teacher's inspiration. It is based on the students' independent and independent learning and cooperative discussion. The current teaching materials are the basic exploration contents, and the student's surrounding world and living reality are the reference objects, providing students with adequate Students are free to express, question, explore, and discuss problems, allowing students to apply their own knowledge to solve practical problems in a variety of ways, such as individual, group, and collective[5].

To develop inquiry-based teaching is to create conditions for students to explore and learn, so that they can cultivate the ability to explore the natural research needed to participate in the process of acquiring knowledge, and form the scientific spirit and scientific attitude to explore the unknown world. Compared with non-inquiry teaching, inquiry teaching has six characteristics: (1)aims at 
cultivating scientific literacy; (2)emphasizes the process of obtaining results and knowledge; (3) applies knowledge to study; (4) emphasizes participation of all; (5) is student-centered; (6) Emphasize the significance of inquiry learning[6].

\section{Questionnaire of Students' Inquiry Ability.}

\section{Survey Objective, Scope and Method}

The scope of the survey and the target were 1,300 teachers and students in Dafang No. 1 Middle School, Dafang County, Guizhou Province. The survey methods are mainly interviews and questionnaire surveys.

\section{Investigation Results and Analysis}

In the survey of students, questionnaires and discussions were mainly conducted on several aspects such as student's interest in learning and motivation, experimental teaching, classroom teaching methods, and inquiry activities[7].

Learning Interest and Teaching Methods

According to the survey, the purpose of most students' learning is to cope with college entrance examinations, increase knowledge, and improve their own quality. Only $21.8 \%$ of students are truly interested in knowledge and hobby. Nearly $40 \%$ of students feel content is too boring and learning difficulties. The main reason for students' learning difficulties lies in the fact that teachers' teaching methods do not effectively guide learning interests and make students feel bored. From this we can see that teachers' changing teaching concepts, changing teaching methods and teaching behaviors are urgent requirements for students.

The survey results also show that students are most interested in the exploratory experiments and knowledge close to life for the rich and varied teaching contents of the new textbooks currently used by Jiangsu Education Press, followed by beautiful pictures, rich information, and expanded visual field. day. Explain that the content system and writing style of the new textbooks are in line with the needs and psychological characteristics of middle school students. The survey found that students' satisfaction with teacher's classroom teaching is relatively high, $73.7 \%$ of students are satisfied, and $22 \%$ of students are basically satisfied. $72 \%$ of students believe that teachers often inspire thinking and guide inquiry by setting problem scenarios and organizing interactive activities[8]. The inquiry teaching method has already entered the classroom and played its role. However, there are few teachers who can organize and instruct students to conduct extra-curricular studies. Most students welcome and are willing to accept inquiry learning. They prefer to study through classmates through experiments and discussion exchanges. Mechanical rote learning is the most annoying way for students to learn. With regard to classroom interaction, class discussion, hands-on experimentation, and games are what most students like. The classroom questions that teachers are most accustomed to use are least popular among students. It can be seen that the content and value of the new curriculum and the changes in the teaching methods of teachers are gradually having a positive effect on students' interest in learning. However, the method of inquiry teaching in the classroom is relatively simple, and communication between teachers and students is still based on questioning. This is because teachers have long been accustomed to their authoritative status and have not been able to change the role of teachers in a timely manner. Teachers need to contrast the three-dimensional teaching objectives of the new curriculum, constantly reflect on their own teaching behavior, and constantly improve teaching methods and teaching methods. First of all, we must have a correct position for ourselves, change our authority status, and regard ourselves as a student's learning assistant, guide, and helper. If teachers and students can communicate and cooperate on an equal and friend-like basis during the inquiry process, it is believed that students' interest and enthusiasm for learning will increase.

The Experimental Teaching Situation

Experiments are an important part of the high school curriculum. Through the experimental process, students can deepen their understanding of knowledge, master experimental methods and skills, experience the process of scientific research, germination and innovation. Through the survey, 
the students found that the students had a full understanding of the role of the experimental class. Most students thought that the experimental class could not only exercise the ability to understand, deepen the understanding of the basic knowledge, and learn scientific inquiry methods, but more importantly, it could stimulate interest in learning and inspire innovation. thought. However, the experimental class did not perform well. Only $31 \%$ of the students chose to conduct their own hands-on experiments. Most of the experiments were demonstrated by teachers. Twenty-six percent of students rarely enter the laboratory to do their own experiments. Even some teacher demonstration experiments are rarely done. The proportion of teachers who occasionally do demonstration experiments is only $19 \%$. The experiment was done by writing and drawing on the blackboard[9]. Students were then required to memorize experimental principles and items, and deviate from the objectives of experimental teaching. Many students expressed dissatisfaction with the current status of the experimental class. They showed a strong desire to experiment and asked for more opportunities for themselves to experiment.

Results and Analysis of Teacher Surveys

I conducted questionnaires, seminars, and random lectures on teachers. I conducted surveys on four aspects of teacher education concepts, the use of new textbooks, the development of inquiry learning, and problems and difficulties in the implementation of new curriculum. Through investigation, it can be found that more than $90 \%$ of teachers feel pressure in the face of the new curriculum reform. Through the study of curriculum standards and related materials and training at all levels, teachers have a clear understanding of the goals and tasks of the new curriculum reform. Facing the new curriculum, the concept of scientific inquiry and the three-dimensional teaching objectives, it is clearly aware of the concept of changing the curriculum. It is the teacher's top priority to change teaching behavior and improve one's own quality and ability. Many teachers have been actively involved in the new curriculum reform and actively promote their own quality and ability through their own learning, cooperation with colleagues, training and other channels[10].

\section{Conclusion}

After researching "introspective teaching of high school under the new "curriculum standards," we found that inquiry teaching can effectively promote students' knowledge construction and ability development. Inquiry-based teaching embodies the teaching principles of "teaching-oriented, learning-centered"; The teaching is democratic and cooperative; it cultivates the student's thinking independence, profoundness, creativity and criticality; it embodies the efficiency of learning efficiency; and it embodies the principles of teaching comprehension. Under the guidance of teachers, students can discover the self and self-understand by exploring the subtleties of knowledge, so as to improve the efficiency of classroom learning. The results of teaching practice confirmed that inquiry teaching can develop students' intelligence, develop students' creative thinking, help students develop their own learning abilities, and can guide students to learn and learn scientific research methods. It has a better understanding of students' knowledge construction and ability development. Good promotion effect. Therefore, it is very important to train students' inquiry ability.

In general, senior high school students in Dafang County Middle School have a good ability to explore, and the development of various elements of inquiry ability is not very balanced. Most students have a certain ability to infer theoretical evidence, but lack the ability to ask questions, design experiments, reflect, and criticize. Imagination and thinking ability are relatively good, but they question the ability of innovation and the ability to connect theory with practice. This shows that there is a good foundation for conducting inquiry teaching, and it also explains the necessity of carrying out inquiry teaching methods and techniques.

\section{References}

[1] Lee, J. C. K., \& Yin, H. B. (2011). Teachers' emotions and professional identity in curriculum reform: A Chinese perspective. Journal of Educational Change, 12(1), 25-46. 
[2] National Research Council. (2006). America's lab report: Investigations in high school science. National Academies Press.

[3] Hand, B., \& Prain, V. (2002). Teachers implementing writing - to - learn strategies in junior secondary science: A case study. Science education, 86(6), 737-755.

[4] Hofstein, A. (2004). The laboratory in chemistry education: Thirty years of experience with developments, implementation, and research. Chemistry education research and practice, 5(3), 247-264.

[5] Bowe, R., Ball, S. J., \& Gold, A. (2017). Reforming education and changing schools: Case studies in policy sociology (Vol. 10). Routledge.

[6] Wang, J., \& Jou, M. (2016). Qualitative investigation on the views of inquiry teaching based upon the cloud learning environment of high school physics teachers from Beijing, Taipei, and Chicago. Computers in Human Behavior, 60, 212-222.

[7] Zhang, F., \& Liu, Y. (2014). A study of secondary school English teachers' beliefs in the context of curriculum reform in China. Language Teaching Research, 18(2), 187-204.

[8] Ary, D., Jacobs, L. C., Irvine, C. K. S., \& Walker, D. (2018). Introduction to research in education. Cengage Learning.

[9] Ramnarain, U. D. (2014). Teachers' perceptions of inquiry-based learning in urban, suburban, township and rural high schools: The context-specificity of science curriculum implementation in South Africa. Teaching and teacher education, 38, 65-75.

[10]Wang, T. (2016). School leadership and professional learning community: Case study of two senior high schools in Northeast China. Asia Pacific Journal of Education, 36(2), 202-216. 